\title{
Erratum to: The Mitogen-Activated Protein Kinase (MAPK) Signaling Pathway as a Discovery Target in Stroke
}

\author{
Jing Sun ${ }^{1} \cdot$ Guangxian Nan ${ }^{1}$
}

Published online: 28 May 2016

(C) Springer Science+Business Media New York 2016

Erratum to: J Mol Neurosci

DOI 10.1007/s12031-016-0717-8

The original version of this article unfortunately contained mistakes in Table 1. We apologize to all readers and make the following corrections:

1. In Table 1 continued, under Outcome column, sixth row, the statement "Prevent cerebral blood w reduction" should be changed to "Prevent cerebral blood flow reduction".

2. In Table 1 continued, under Outcome column, seventh row, the statement "Raf inhibitor SB386023-b" should be changed to "Prevent reduction in regional CBF and neurological scores".

3. In Table 1 continued, under Outcome column, eighth row, the statement "Raf inhibitor SB386023-b" should be changed to "Prevent the reduction of cerebral blood flow".

The online version of the original article can be found at http://dx.doi.org/ 10.1007/s12031-016-0717-8.

Guangxian Nan

ngx0415@163.com

Jing Sun

sunjing8801@gmail.com

1 Department of Neurology, China-Japan Union Hospital of Jilin

University, No. 126 Xiantai Street, Changchun 130000, Jilin, China 